\title{
Groundwater Management under the Kabu-ido System in Noubi Plain, Japan, 1810s 1860s
}

\author{
Takahiro Endo \\ College of Sustainable System Sciences, Osaka Prefecture University, Osaka 5998531, Japan
}

\begin{abstract}
The purpose of this paper is to clarify how the Kabu-ido system can be employed to successfully regulate groundwater pumping. This was accomplished by analyzing surviving historical documents, including budgetary notes and a diary. The Kabu-ido system was a customary institution for groundwater management in a ring levee area of the Noubi Plain in Japan that consisted of three programs: restriction of groundwater pumping through a permit system, groundwater pricing and economic compensation. The system was created in the 1810 s and survived for 100 years. This paper covers the Kabu-ido system from the 1810s to the 1860s, the first half of the 100-year history. Excessive groundwater pumping is not a new environmental problem. Although many case studies have investigated remedial actions, few have investigated how local residents addressed the problem before the 20th century because of a lack of documents. The Kabu-ido system is an exception in which of the procedure was documented in writing. The historical data indicate that it was a pioneering institution for groundwater management.
\end{abstract}

Key words: Kabu-ido system, history, groundwater management, self-organized restriction and Japan.

\section{Introduction}

Water resource development by dams has been the primary method employed to meet water needs throughout the 20th century. However, this approach is facing the limits because of a lack of dam sites and environmental concerns. As groundwater receives increasing attention as an alternative, concern regarding excessive groundwater pumping is increasing worldwide [1].

This problem is not new, and it is known to have occurred 200 years ago in some villages in the Tokai region of Japan. The affected communities created an institution for groundwater management known as the Kabu-ido system to address issues associated with groundwater pumping. This paper describes how groundwater pumping was controlled under the Kabu-ido system.

Many case studies have dealt with the history of excessive groundwater pumping in the United States [2-5], China [6], England [7], Mexico [8],

Corresponding author: Takahiro Endo, Ph.D., research field: water policy.
Saudi Arabia [9] and Japan [10, 11]. However, none of these cases are more than 130 years old. In addition, while remedial action was taken after the 20th century in all cases, few instances have described how excessive groundwater pumping was addressed before the 20th century because of a lack of documents. The Kabu-ido system is an exception in that written records were kept, making it a pioneering institution for groundwater management.

\section{The Kabu-ido System}

The Kabu-ido system was a customary institution for groundwater management in a ring levee area of the Noubi Plain in Japan. The ring levees were developed at the confluence of three large rivers: the Ibi, Nagara, and Kiso. Many villages and towns were surrounded by successive levees to prevent against flooding. Such ring levees are often locally called waju in Japanese.

Early in the 19th century, a conflict caused by groundwater pumping occurred in the ring levee area. This conflict was mitigated by restriction of groundwater pumping through a permit system, groundwater pricing and economic compensation. 
These programs gradually developed and were later referred to as the Kabu-ido system.

In Japanese, kabu means "the privilege to do business" [12] and ido means "well"; therefore, Kabu-ido can be interpreted as meaning "privileged well" or "the special right to dig wells". The Kabu-ido system existed within the Fukuzuka, Takasu and Shimogasa Ring Levees. This study focuses on the Fukuzuka Ring Levee, where the Kabu-ido system was first developed. Fig. 1 shows the ring levee area in approximately 1870 based on Ref. [13].

In the Fukuzuka Ring Levee, the Ido-soudai played the primary role in regulation of groundwater pumping. While ido means "well" as mentioned before, soudai means "representative". Accordingly, Ido-soudai can be considered "well managers". However, no studies have investigated the function of the Ido-soudai. Therefore, this study was conducted to clarify how the Kabu-ido system could succeed in regulating groundwater pumping while focusing on the function of the Ido-soudai.

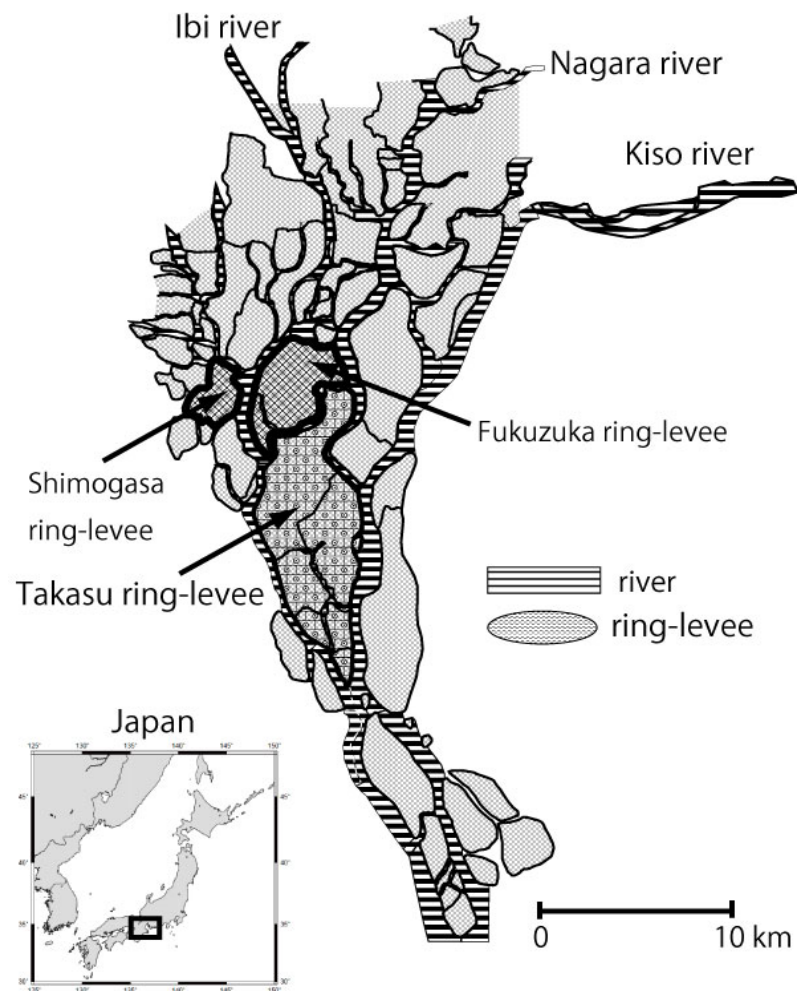

Fig. 1 Ring levees in the Noubi Plain in approximately 1870.
The Kabu-ido system in the Fukuzuka Ring Levee was created in the $1810 \mathrm{~s}$ and survived for 100 years. This paper clarifies the Kabu-ido system from the 1810 s to the 1860 s. While this paper covers the first half of the 100-year history of the Kabu-ido system, the latter half will be studied in a different paper.

\section{Methods}

The Kabu-ido system in the Fukuzuka Ring Levee has been investigated since the 1930s. Refs. [14, 15] clarified its origin based on a wide review of historical documents. These studies were followed by more recent studies $[16,17]$.

These studies clarified the history of the Kabu-ido system, but did not deal with institutional aspects of the system. Specifically, it is still necessary to investigate how the Kabu-ido system was designed as an institution for groundwater management and which components in the institution prevented uncoordinated groundwater pumping.

To accomplish this, descriptions in a record known as the Nishimatsu Diary were evaluated. This diary was made by the Nishimatsu family, who lived in the Village of Nishijo within the Fukuzuka Ring Levee. The diary covers 60 of the 75 years, which range from 1810 to 1884 . Although the diary was investigated in depth [18], descriptions of wells are very limited because the primary goal of that study was to show the daily life of the Nishimatsu family.

Use of the Nishimatsu Diary for investigation of the Kabu-ido system is important for two reasons. First, the diary is a personal document made with no intention of publication. Therefore, the reliability of the content is high, even though it reflects subject of the writer [18]. Second, the diary covers a span for which little information about the Kabu-ido system is available. The surviving historical documents mainly covered the 1810 s, when the Kabu-ido system was created, and the 1870s, when the system was largely modified [15]. Conversely, few records made between these two periods could be found. Therefore, how the Kabu-ido 
actually operated after its creation has remained unknown. Although the Nishimatsu Diary is very useful for analysis of operation of the Kabu-ido system, no previous studies have made use of the diary.

\section{Development of the Kabu-ido System in the Fukuzuka Ring Levee}

\subsection{Water Issues in the Fukuzuka Ring Levee}

The Fukuzuka Ring Levee extends $5 \mathrm{~km}$ from east to west and $7 \mathrm{~km}$ from north to south. The altitude ranges from $1 \mathrm{~m}$ to $5 \mathrm{~m}$, with the lowest area being found in the central part of the ring, resulting in a basin shape. Generally speaking, the altitude of its northeast portion is higher than that of the southeast [19].

Villages located in higher places are known as upper villages and those in lower areas are called lower villages. There were 10 upper villages and 6 lower ones within the ring levee. Lower villages are indicated by numbers in parentheses. Fig. 2 shows the location of the villages based on Ref. [20].

Some of the upper villages diverted water from the Ibi River, but began to use groundwater after the advent of pumping techniques in the late 18th century. Accumulated drainage from artesian wells in the upper villages increased flood risk and hindered agricultural activities in the lower villages [21].

\subsection{Internal Agreement Regarding Artesian Wells in the} Fukuzuka Ring Levee of 1812 (Hereafter Referred to as the 1812 Agreement)

There was a major dispute between the upper and lower villages in 1801, after which an internal agreement regarding artesian wells was reached between the upper and lower villages in July 1812 [22]. This agreement includes the following articles:

- Article 1: The number of artesian wells is confined to 45. No additional wells are permitted. If any upper village breaches this article, all existing wells in the village must be eliminated;

- Article 2: Four people (two from the upper and two from the lower villages) act as well operators. A

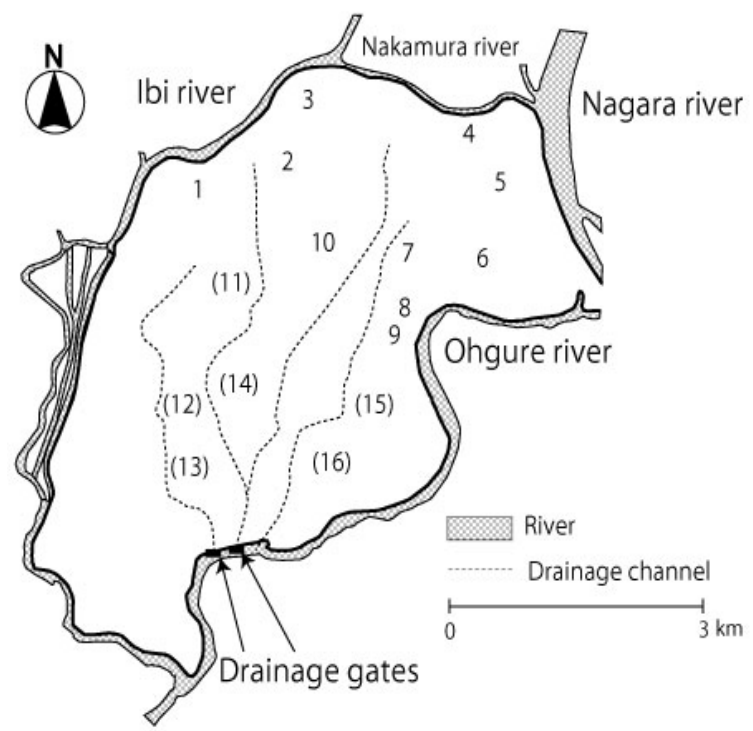

\begin{tabular}{|c|c|c|}
\hline & Number & Village name \\
\hline \multirow{10}{*}{$\begin{array}{c}\text { The } \\
\text { upper } \\
\text { villages }\end{array}$} & 1 & Fukuzuka \\
\hline & 2 & Sato \\
\hline & 3 & Nanba \\
\hline & 4 & Hondo \\
\hline & 5 & Nishijo \\
\hline & 6 & Niremata \\
\hline & 7 & Niremata-Shinden \\
\hline & 8 & Ohyabu \\
\hline & 9 & Kami-Ohgure \\
\hline & 10 & Nakagoh \\
\hline \multirow{6}{*}{$\begin{array}{c}\text { The } \\
\text { lower } \\
\text { villages }\end{array}$} & (11) & Fukuzuka-Shinden \\
\hline & $(12)$ & Moike-Shinden \\
\hline & (13) & Miru-Shinden \\
\hline & (14) & Nakagoh-Shinden \\
\hline & (15) & Gotango-Shinden \\
\hline & (16) & Shimo-Ohgure-Shinden \\
\hline
\end{tabular}

Fig. 2 Map of the Fukuzuka Ring Levee.

well must be opened in the presence of these operators;

- Article 3: The annual salary of a well manager is 1 ryo (unit of money at the time). The upper villages pay this salary;

- Article 4: Each well must be locked and the key deposited with well managers of the upper villages in a key box. The key to the key box is deposited with well managers of the lower villages;

- Article 5: A broken well must be repaired to prevent unexpected drainage;

- Article 6: Anyone who breaks the lock to secretly open the wells at night must be strictly warned;

- Article 7: A well owner who intentionally lets groundwater flow under the guise of a broken well must have the well buried in the presence of well managers from the lower villages; 
- Article 8: A well inside a house must be buried;

- Article 9: If an irrigation well does not function adequately, the owner can dig another well in the presence of a well manager from the lower villages;

- Article 10: When the drainage gates in the lower villages are closed, wells must not be opened, even in case of drought;

- Article 11: If water flows out from a buried well, the well must be completely buried in the presence of the well managers. If residents of the lower villages find that upper village residents use the well without reporting its use, the former residents should consult the local magistrate office.

This agreement was later modified by the "Agreement on Artesian Wells and Changes in Drainage Channels of 1877 (hereinafter the 1877 agreement)". Whereas the word ido is found in the 1812 agreement, the word Kabu-ido is not. Ref. [22] pointed out that the Kabu-ido system was established in the 1877 agreement. The three pillars of the system, restriction of groundwater pumping by a permit system, groundwater pricing and economic compensation, were completed in the 1877 agreement and the word Kabu-ido was first used. Therefore, strictly speaking, the institution established by the 1812 agreement cannot be called the Kabu-ido system because it merely satisfies one pillar (restriction of groundwater pumping by a permit system). However, in this paper, the institution established by the 1812 agreement is also treated as the Kabu-ido system because it provided the foundation for the system developed in 1877.

\section{Institutional Structure of the Kabu-ido System in the Fukuzuka Ring Levee}

\subsection{Well Association}

Villages in the Fukuzuka Ring Levee did not always act as one unit, but instead created ad-hoc associations to deal with various social problems [19]. For example, all of the villages joined a single levee association with the purpose of maintaining the ring levee. Conversely, there was a well association organized by only
10 upper villages to deal with problems related to groundwater use. The location and names of the 10 villages that created the well association are shown in Fig. 2, and the following entries were recorded in the Nishimatsu Diary:

"A meeting of the well association to discuss wells for drinking purposes was held at the Ohyabu community house. I joined the meeting along with representatives from 10 upper villages".

Although it is not clear when the well association was established, a few village public expenditure notes indicate that the association existed as early as the beginning of the 19th century.

"41 monme and 6 bu were allocated to our village for matters pertaining to wells and the well association (monme and bu were units of money at the time)".'

This record implies that the well association existed before the 1812 agreement. However, there is no record of a well association in the lower villages. Nevertheless, there was an organization in which the lower villages conducted collective decision-making, as mentioned later.

\subsection{Wells as a Public Asset}

Mura-nyuyou-cho is a record of public expenditure that shows a village's annual expenditures. Generally speaking, an item that appeared in the expenditure note can be considered a public issue at the time. For example, the maintenance fee for levees and drainage gates often appears in the expenditure note of villages located in the ring levee area. This reflects how often flood events occurred in this area. In the Fukuzuka Ring Levee, the expenditure notes of Nishijo Village survive. The record of 1801 cited above implies that wells were considered a public asset in the villages as early as the 19th century.

The 1812 agreement reinforced the public ownership of the wells. According to a survey conducted in May 1812 (immediately before the agreement), the number

\footnotetext{
${ }^{1}$ The Nishimatsu Diary, January 12, 1850.

${ }^{2}$ Nishijo Village public expenditure note of 1801.
} 
Table 1 Changes in number of wells in the Fukuzuka Ring Levee.

\begin{tabular}{llllllll}
\hline \multirow{2}{*}{ Number } & Village & \multicolumn{7}{c}{ Year } \\
\cline { 3 - 8 } & 1812 & 1844 & 1851 & 1852 & 1859 & 1875 \\
\hline 1 & Fukuzuka & 9 & 8 & 8 & 8 & 8 & 8 \\
2 & Sato & 6 & 6 & 6 & 6 & 6 & 6 \\
3 & Nanba & 4 & 4 & 4 & 4 & 4 & 4 \\
4 & Hondo & 1 & 0 & 0 & 0 & 0 & 0 \\
5 & Nishijo & 4 & 3.666 & 3.666 & 3.666 & 3.666 & \\
6 & Niremata & 5 & 4.666 & 4.666 & 4.666 & 4.666 & 8.333 \\
7 & Niremata-Shinden & 4 & 4.666 & 4.666 & 4.666 & 4.666 & 4.666 \\
8 & Ohyabu & 4 & 6 & 6 & 6 & 6 & 6 \\
9 & Kami-Ohgure & 6 & 6 & 6 & 6 & 6 & 6 \\
10 & Nakagoh & 2 & 2 & 2 & 2 & 2 & 2 \\
\hline
\end{tabular}

Source: Internal agreement on artesian wells in Fukuzuka Ring Levee of 1812 and cost-sharing notes on well management for 1844, $1851,1852,1859$ and 1875 .

of existing and proposed wells was $123 .^{3}$ However, this number was drastically reduced to 45 by the 1812 agreement to decrease impoundment damage to the lower villages by restricting the number of artesian wells. ${ }^{4}$ After this agreement, the upper villages were not able to construct wells without permission from the lower villages, indicating that the problem of wells became not only a public matter within a single village, but also a matter of public concern for the inter-village society.

\subsection{Restricted Well Construction}

Table 1 shows the changes in the number of wells from 1812 to 1875 based on information from the 1812 agreement and some cost-sharing notes regarding well management. A cost-sharing note on well management is a record of public expenditures by the well association. Village numbers $1 \sim 10$ in Table 1 are the same as those in Fig. 2. As indicated in Table 1, the limit on the number of wells was strictly observed. The note regarding the well management of 1875 treated Nishijo as part of Niremata and counted the total number of wells in both villages; Therefore, no data are included in Table 1 for Nishijo in 1875.

\footnotetext{
${ }^{3}$ Survey on the number of wells, May 1812 .

${ }^{4}$ Internal agreement regarding artesian wells in the Fukuzuka Ring Levee of 1812.
}

It should be noted that allocation of wells was not fixed. The following description in the Nishimatsu Diary implies that there was re-allocation of wells among villages:

"A meeting of the well association was held at the Ohyabu community house to discuss well allocation between the Villages of Hondo and Ohyabu. While the former lent a well to the latter last year, it plans to use the well this year. Ohyabu Village agreed with the proposal. Initially, the Village of Ohyabu was entitled to use 4 wells, but it has used 6 wells. A solution to this problem is not easy. The past agreement should be observed...". 5

A few things should be investigated in future research. According to the 1812 agreement, the Village of Hondo also had a well. However, it was not found in the cost-sharing notes on well management. It is not clear why Hondo did not take part in the well association. A possible reason is that the village did not use the well every year as mentioned above. Therefore, it was not regarded as a member of the association. In addition, a few villages (Nishijo, Niremata and Ohyabu) had fractional well numbers, such as 3.666 and 4.666. Although there is no way to be certain, this suggests that some of the wells were shared by villages.

\footnotetext{
${ }^{5}$ The Nishimatsu Diary, April 5, 1863.
} 


\subsection{Self-organized Restriction}

Monitoring and sanctioning of illegal pumping is a large problem in groundwater management, even today. Currently, government organizations are in charge of groundwater management and play roles in monitoring and sanctioning. However, in the case of the Kabu-ido system, such activities were conducted by the parties themselves. Monitoring and sanctioning without external authority often provokes a free-rider problem [23]. For example, monitoring illegal wells reduces drainage risk, which is a public good to all lower villages. Therefore, if a lower village conducts such monitoring activities, other villages can enjoy the benefit without contributing. In such a situation, no village will have an incentive to monitor and penalize because they will each expect other villages to do so.

However, Article 3 of the 1812 agreement solved this problem. The lower villages made the upper villages pay the cost of monitoring activities to avoid the free-rider problem. In addition, Article 1 includes a rule of joint responsibility. It can be inferred that the rules not only made the penalty system practical, but also provided the upper villages with an incentive to check for illegal users.

Although explaining the 1877 agreement is beyond the scope of this paper, it introduced additional solutions including a well numbering and a reward system. Well numbering not only imposed a cap on the total number of wells, but also reduced monitoring costs. It enabled patrolmen from the lower villages to quickly distinguish between authorized and unauthorized wells because they could easily identify wells without a number and those with an unauthorized duplicate number. In addition, the personal reward system for well detection increased the personal benefit of monitoring activities to promote the voluntary provision of a public good. However, introducing a personal reward system may provoke another free-rider problem of preparing the reward.
Accordingly, the 1877 agreement includes an article that prevents this problem by assigning the responsibility for the reward to the upper villages. ${ }^{6}$

\section{Function of the Ido-soudai}

\subsection{The Ido-soudai}

As mentioned above, the 1812 agreement incorporated various methods to make the upper villages observe limits on the number of wells. The Ido-soudai played an important role in execution of the 1812 agreement.

Before explaining the function of the Ido-soudai, the administrative system implemented by the villages at that time needs to be described. Generally, mura-yakunin refers to a village decision-making body. This body consisted of three types of officials, shouya, kumigashira and hyakusho-dai. Each village in the Fukuzuka Ring Levee had its own mura-yakunin, which played many roles in the village, including tax collection, managing religious life, disaster prevention, handling legal issues and maintaining law and order [21].

While the mura-yakunin was in charge of public administration in a village, the Ido-soudai were only responsible for groundwater management. The Ido-soudai consisted of four people, two from the upper villages and two from the lower villages.

As mentioned above, a cost-sharing note on well management is a record on public expenditure by the well association. This note was published under the name of the Ido-soudai from the upper villages. Therefore, it can be inferred that the Ido-soudai from the upper villages were representatives of the well association. Conversely, there was no well association in the lower villages. However, the following record is found in the Nishimatsu Diary:

"I went home because patrolmen from the six lower villages visited to check my wells".

\footnotetext{
${ }^{6}$ Agreement on Artesian Wells and Changes in Drainage Channels of 1877.

${ }^{7}$ The Nishimatsu Diary, March 12, 1865.
} 
This suggests that there was also a body for collective-decision making in the lower villages. The Ido-soudai of the lower villages took responsibility for monitoring activities and also negotiated with Ido-soudai of the upper villages on behalf of the residents.

It is not certain that the Ido-soudai was established by the 1812 agreement, although it referred to the Ido-soudai. A record from the Nishimatsu Diary dated August 2, 1810 states:

"There was a meeting regarding wells at the Ohyabu community house and requests to dig new wells came from the following villages: Kami-Ohgure, Ohyabu, Niremata, Niremata-Shinden, Nishijo, Hondo, Nanba and Sato. Fukusuke (person's name) was sent to Nakagoh to discuss how this should be promoted...".

This strongly suggests that there was already been a decision-making body within some of the upper villages before the 1812 agreement. It can be inferred that the Ido-soudai was not suddenly established by the 1812 agreement, but instead based on a customary institution of decision-making.

\subsection{Rotation System}

Which village provided the Ido-soudai? The following description can be found in the Nishimatsu Diary:

"Today, a message came from the lower villages that patrolmen would be sent to Nishijo tomorrow. Toubei (a person's name) and I were appointed as the Ido-soudai this year". 8

In addition, a few surviving cost-sharing notes on well management were issued under the name of the Ido-soudai of the upper villages. ${ }^{9}$ Based on the information, a list of villages that provided the Ido-soudai from the $1820 \mathrm{~s}$ to $1860 \mathrm{~s}$ is shown in Table 2. This list excludes years for which no diary is available or no information is contained in the diary on villages that provided the Ido-soudai.

The list indicates that there was a rotation system for appointment of the Ido-soudai and suggests that the Village of Niremata played a large role in groundwater management in the upper villages, providing the Ido-soudai for two or three successive years. Less information is available regarding the Ido-soudai from the lower villages. While Moike-shinden and Nakagoh-shinden provided the Ido-soudai from 1830s to $1840 \mathrm{~s}$, Gotango-shinden filled the role in the $1860 \mathrm{~s}$. Accordingly, it can be inferred that a rotation system also existed for the lower villages.

\subsection{Functions of the Ido-soudai}

Various authorities were given to the Ido-soudai by the 1812 agreement, including permission to open a well (Article 4), destroy a well (Article 7), change a well location (Article 9) and implement countermeasures against a drainage accident (Article 11). Moreover, the Ido-soudai of the upper villages made a cost-sharing note on well management every December, although it was not written in the 1812 agreement. The Nishimatsu Diary shows that, not only did the Ido-soudai exercised these authorities, but they also played roles other than those depicted in the 1812 agreement.

The function of the Ido-soudai can be clarified by contrasting the authorities depicted in a public document such as the 1812 agreement with those in the Nishimatsu Diary. Unfortunately, the description of wells in the diary was so fractioned that no information was available showing the whole process of groundwater use in a year. Therefore, the function of the Ido-soudai was explained by connecting various descriptions of wells in different years. Although exact reconstruction is impossible because the activities of the Ido-soudai might change every year, it is possible to abstract their typical activities based on descriptions from different years, considering that rural people of 200 years ago were much conservative and their social life did not change drastically.

\footnotetext{
${ }^{8}$ The Nishimatsu Diary, April 16, 1835.

${ }^{9}$ Cost-sharing notes on well management of 1852 .
} 
Table 2 Rotation of the Ido-soudai from 1820s to 1860s.

\begin{tabular}{lllll}
\hline Year & The Ido-soudai of the upper villages & \multicolumn{2}{l}{ The Ido-soudai of the lower villages } \\
\hline 1826 & Gotango & - & - & - \\
1833 & Niremata & - & - & - \\
1835 & Niremata-Shinden & Nishijo & - & - \\
1836 & Niremata & Ohyabu & - & - \\
1838 & - & - & Moike-Shinden & Nakagoh-Shinden \\
1841 & Niremata & - & Moike-Shinden & Nakagoh-Shinden \\
1844 & Niremata & Ohyabu & Moike-Shinden & Nakagoh-Shinden \\
1845 & Niremata & Sato & - & - \\
1851 & Niremata & Niremata-Shinden & - & - \\
1852 & Niremata & Ohyabu & - & - \\
1853 & Niremata & Sato & Fukuzuka-Shinden & Nakagoh-Shinden \\
1854 & Nanba & - & - & - \\
1860 & Niremata & Sato & Fukuzuka-Shinden & Gotango-Shinden \\
1861 & Niremata & - & - & - \\
1862 & Fukuzuka & Nanba & - & - \\
1863 & Nakagoh & Ohyabu & Gotango-Shinden & Miru-Shinden \\
1864 & Fukuzuka & Nanba & - & - \\
1865 & Niremata-Shinden & Nishijo & Nakagoh-shinden & - \\
1866 & kami-Ohgure & Niremata & Gotango-Shinden & Miru-Shinden \\
1868 & Niremata & Ohyabu & - & - \\
1869 & Fukuzuka & Nanba & Gotango-shinden & Miru-shinden \\
\hline
\end{tabular}

Source: The Nishimatsu Diary and cost-sharing notes on well management of 1845, 1851 and 1852.

According to the Nishimatsu Diary, well management began in April, with a few exceptions. At this time, the lower villages sent patrolmen to the upper villages and the latter served the patrolmen food. The following description can be found in the diary:

"Today, patrolmen finished checking wells in Fukuzuka and Nanba". 10

"It is cloudy and the southern wind is strong today. Patrolmen came to my house. I served alcoholic drinks to them". ${ }^{11}$

"Sen-uemon (a person's name) of Niremata-shinden came. He and I are the Ido-soudai for the upper village this year. The lower villages sent a message that well patrol would start on May 4 from Fukuzuka village, as usual". ${ }^{12}$

It can be inferred that patrol activities were conducted every year from the description "as usual" in the record of 1865 . Rice-farming was the primary

\footnotetext{
${ }^{10}$ The Nishimatsu Diary, April 17, 1835.

${ }^{11}$ The Nishimatsu Diary, April 21, 1844.

${ }^{12}$ The Nishimatsu Diary, April 1, 1865.
}

industry in the Fukuzuka Ring Levee at that time. According to the diary, rice farming usually began in May, at which time demand for irrigation water increased. Therefore, patrols began in April so that the lower village could check the irrigation wells immediately before the planting season. This can be inferred by the following description of April 29, 1836:

"Today patrolmen came. Riheiji (a person's name) took care of them. They requested to see destroyed wells and old wells so we took them to the locations of such wells".

Although it is not written in the 1812 agreement, any village that wanted a well first applied to the Ido-soudai of the upper villages. The request was then sent to the Ido-soudai of the lower villages. This shows that the Ido-soudai negotiated between the upper and lower villages.

"A meeting on the well was held in the evening. Tousaburo (a person's name) visited Niremata to ask 
the Ido-soudai for permission to open a provisional well". 13

"A request to open a provisional well was sent to the Ido-soudai of the lower villages. The answer came. A meeting was held". 14

According to Article 4 of the 1812 agreement, each well was locked. This means a well could not be used without permission from both the upper and lower villages. The Nishimatsu Diary includes a description that shows the lock system was actually implemented. In addition, the diary indicates that wells were opened when the Ido-soudai of the lower villages were present.

"I asked Gotango Village to open the gate of the wells. I got the key to open the gate this afternoon". ${ }^{15}$

"A well was constructed in Imao. The Ido-soudai of the upper and lower villages was present". 16

The same procedure was applied to change a well location. Article 9 of the 1812 agreement said permission from the Ido-soudai was necessary to change the location of a well. The following records show such changes were implemented when the Ido-soudai of the lower village were present.

"The Ido-soudai of the lower villages, Chuji of Nakagoh-shinden and Magouemon of Moike-shinden, came together. A well inside Yuuske's house was replaced with a new one. Water flew up". ${ }^{17}$

A well was not always available throughout the irrigation season, and sometimes they were required to be closed temporarily in cases of heavy rain.

"It is cloudy and winds from east today. It rained heavily at night. A letter came that required a well to be shut down in the evening". ${ }^{18}$

The lower villages were concerned with technical control of groundwater pumping. Therefore, they regulated wells with special equipment to increase the pumping volume.

"Patrolmen came. Hanzaemon, the Ido-soudai from

\footnotetext{
${ }^{13}$ The Nishimatsu Diary, July 21, 1844.

${ }^{14}$ The Nishimatsu Diary, June 27, 1853.

${ }^{15}$ The Nishimatsu Diary, May 29, 1826.

${ }^{16}$ The Nishimatsu Diary, July 25, 1844.

${ }^{17}$ The Nishimatsu Diary, April 20, 1838.

${ }^{18}$ The Nishimatsu Diary, May 21, 1826.
}

the upper villages, said that Kumezo's wells were equipped in such a way that the volume of flowing water was very large and he was told to remove the equipment". 19

Finally, there was a record that showed the Ido-soudai were present to see a well shut down:

"The Ido-soudai of the lower villages, Okuemon of Nakagoh-shinden and Magouemon of Moike-shinden, and the Ido-soudai from the upper villages, Hanzaemon, were present to see Gouemon's well closed". 20

\section{Conclusions}

Here, the method by which groundwater pumping was controlled under the Kabu-ido system was clarified, while focusing on the function of the Ido-soudai. The 1812 agreement was very important because it established the basic structure of the Kabu-ido system. Additionally, it incorporated a rule of joint responsibility to provide the upper villages with an incentive to check for illegal users by themselves. The agreement also required the upper villages to pay the cost of monitoring activities by the lower villages. This dual monitoring system enabled self-organized management of groundwater.

The Ido-soudai played the primary role in groundwater management. The Ido-soudai consisted of four people, two from the upper villages and two from the lower villages. The 1812 agreement described the authorities of the Ido-soudai, which included permitting construction of a well, destroying a well, changing the location of a well and dealing with drainage accidents. This paper contrasted the 1812 agreement and description of the Nishimatsu Diary to clarify such authority was really exercised. The diary also shows the Ido-sodai's liaison function, which prompted dialogue between the upper and lower villages, even though it was not depicted in the 1812 agreement.

\footnotetext{
${ }^{19}$ The Nishimatsu Diary, March 24, 1833.

${ }^{20}$ The Nishimatsu Diary, June 29, 1841.
} 
It should be noted that future studies are needed. Specifically, this paper dealt with groundwater management from the 1810 s to the 1860 s, but this is only half of the total history of the Kabu-ido system in the Fukuzuka Ring Levee. The 1812 agreement was later replaced by the 1877 agreement, with the former establishing the basic structure of the Kabu-ido system and the latter completing this structure. The replacement also changed the function of the Ido-soudai. For example, the 1877 agreement included transactions for wells and gave the Ido-soudai the authority to supervise such transactions. Additional studies are needed to determine how this authority was really exercised.

Additionally, a substantial amount of budgetary documents for the Fukuzuka Ring Levee are available. These documents will be very useful for analysis of the fiscal system governing the Kabu-ido system. However, no studies have yet considered these documents. Accordingly, further investigations of these items are warranted to determine how wells were financed and costs were shared among the upper villages.

\section{Acknowledgments}

The texts in this study were originally presented at the Third Conference of East Asian Environmental History (EAEH 2015) held at Kagawa University, Japan from October 22 25, 2015. This work was financially supported by the Asahi Glass Foundation, Societal Adaptation to Climate Change: Integrating Paleoclimatological Data with Historical and Archaeological Evidence (Research Institute for Humanity and Nature Project) and the Japan Society for the Promotion of Science KAKENHI (Grant-in-Aid for Challenging Exploratory Research) grant number 26550101. Historical documents on the Kabu-ido cited are available in the Gifu Prefecture Historical Document Center, Ohgaki City Library and Rikkyo University Library. Special thanks are due to the Population and Family History Project at Reitaku University for providing the translation of the
Nishimatsu Diary made by Narimatsu, Saeko. The views presented are those of the author and should in no way be attributed to these organizations. Responsibility for the text (including any errors) rests entirely with the author.

\section{References}

[1] Wada, Y., Van Beek, L. P. H., Van Kempen, C. M., Reckman, J. W. T. M., Vasak, S., and Bierkens, M. F. P. 2010 "Global Depletion of Groundwater Resources." Geophysical Research Letters 37.

[2] Weschler, L. 1968. Water Resources Management: The Orange County Experience. Davis: Institute of Governmental Affairs, University of California.

[3] Blomquist, W. 1992. Dividing the Waters, Governing Groundwater in Southern California. San Francisco: ICS (Institute for Contemporary Studies) Press.

[4] Gates, J. 2005. "Groundwater Irrigation in the Development of the Grand Prairie Rice Industry, 1896-1950." The Arkansas Historical Quarterly 64 (4): 394-413.

[5] Michel, T. A. 2006. "100 Years of Groundwater Use and Subsidence in the Upper Texas Gulf Coast." In Aquifers of the Gulf Coast of Texas (Texas Water Development Board Report 365), edited by Mace, R. E., Davidson, S. C., Angle, E. S. and Mullican III, W. F. Austin: Texas Water Development Board.

[6] Yi, L., Zhang, F., Xu, H., Chen, S., Wang, W., and Yu, Q. 2011. "Land Subsidence in Tianjin, China." Environmental Earth Sciences 62: 1151-61.

[7] Cook, H. F. 1999. "Groundwater Development in England.” Environment and History 5: 75-96.

[8] Wolfe, M. 2013. "The Historical Dynamics of Mexico's Groundwater Crisis in La Laguna, Knowledge, Resources, and Profit, 1930s 1960s." Mexican Studies 29 (1): 3-35.

[9] Al-Ibrahim, A. A. 1991. "Excessive Use of Groundwater Resources in Saudi Arabia: Impacts and Policy Options." Ambio 20 (1): 34-7.

[10] Endo, T. 2011. "Sinking Cities and Governmental Action: Institutional Responses to Land Subsidence Problem in Osaka and Bangkok." In Groundwater and Subsurface Environments: Human Impacts in Asian Coastal Cities, edited by Taniguchi, M. Tokyo: Springer.

[11] Endo, T. 2015. "Groundwater Management: A Search for Better Policy Combinations." Water Policy 17 (2): 332-348.

[12] Miyamoto, M. 1977. A Study on Kabu Group (Kabu Nakama no Kenkyu). Tokyo: Koudansha. (in Japanese)

[13] Nanno Town. 1977. A History of Nanno Town (Nanno Cho 
Shi). Gifu: Taiyosha. (in Japanese)

[14] Itoh, M. 1934. "On the Ring Levees and the Kabu-ido in Mino.” Economic History Studies (Keizaishi Kenkyu) 14 (2): 171-5. (in Japanese)

[15] Katano, A. 1941. "The Kabu-ido in Fukuzuka and Takasu Ring Levees." Noubi Culture (Noubi Bunka) 1: 47-77. (in Japanese)

[16] Kubota, M. 2008. Living with Rivers: Stories of Nagara, Ibi Rivers (Kawa to Ikiru: Nagara, Ibi Gawa Monogatari). Nagoya: Fubaisha. (in Japanese)

[17] Shimizu, S. 2014. "Fukuzuka Ring Levee and the Kabu-ido." Wanouchi Studies (Wanouchi Gaku Kenkyu) 3: 2-10. (in Japanese)

[18] Narimatsu, S. 2000. Society and Daily Life of Edo-Period in Shouya Diaries (Shouya Nikki ni Miru Edo no Sesou to Kurashi). Kyoto: Mineruba Shobou. (in Japanese)
[19] Ukai, A. 2006. "Association of Villages in Fukuzuka and Takasu Ring Levees for Flood Control in Mino during Late Modern Times." The Geographical Reports (Chiri Gaku Houkoku) 102: 16-32. (in Japanese)

[20] Editorial Committee of Growing Wanouchi. 1996. Growing Wanouchi (Hirakeyuku Wanouchi). Gifu: Wanouchicho. (in Japanese)

[21] Editorial Committee of a History of Wanouchi Town. 1981. A History of Wanouchi Town (Wanouchi Cho Shi). Tokyo: Dai-ichi Hoki Shuppan. (in Japanese)

[22] Sakurai, I. 1934. On the Kabu-ido in Fukuzuka Ring Levee (Fukuzuka Wajuniokeru Kabuidonitsuite). Gifu: Ohgaki City Library. (in Japanese)

[23] Ostrom, E. 1990. Governing the Commons, the Evolution of Institutions for Collective Action. New York: Cambridge University Press. 